\title{
INCORPORATING EXPERIENTIAL LEARNING IN LOWER DIVISION ENGINEERING COURSES
}

\author{
Atousa Hajshirmohammadi and Nilgoon Zarei \\ School of Engineering Science, Simon Fraser University, Burnaby, BC, Canada \\ atousah@sfu.ca, nzarei@sfu.ca
}

\begin{abstract}
Experiential learning" as a method of delivering course material is becoming more recognized in university education, in recent years. This paper is a report on the early phase of a project at the School of Engineering Science at Simon Fraser University which aims at incorporation of experiential learning in lower division courses.

The course considered here is a first year course in Logic Circuits. An example of an assignment given to students which implements the experiential learning method is presented and the results of students' feedback on this method of learning compared to conventional method is summarized.

Future directions for subsequent phases of this project are outlined, namely expansion of this method by adding more examples and incorporation of experiential learning in other lower division courses. Furthermore, implementation of a system to measure the effectiveness of experiential learning method is also considered.
\end{abstract}

Keywords: Experiential Learning, Experiential Education, Engineering Education, Digital Circuits, Logic Circuits.

\section{INTRODUCTION}

"Experiential learning" as a method of delivering course material is becoming more recognized in university education in recent years. Many of North American as well as international universities have formed research teams dedicated to incorporation of experiential education in their curriculum. Simon Fraser University (SFU) in Canada, where the authors are affiliated with, is no exception. The Experiential Education Project at SFU began in late 2010 with a focus on documenting SFU's use of credit-bearing experiential education [1].

Research on experiential and community engagement learning shows that the concept of experiential learning has been mostly applied to Arts and Humanities, less to Natural Sciences, and even less to Engineering. This may at first glance seem rather intuitive considering the closeness of humanities subjects to human experiences.
However, the role of engineering concepts in our modern lives should not be overlooked either.

Incorporation of experiential learning in subjects such as Electrical and Computer Engineering is more easily achieved in upper division courses, through course projects, internships, and capstone projects. However, it is important that students understand the purpose and the application of the theoretical knowledge they are gaining as early as possible, and this can be achieved if they experience with real life examples related to what they learn. For lower division courses, experimental work in laboratory while learning theoretical background in conventional classes is often considered as experiential learning (e.g. [2]). While the importance of experimental work or hands-on experiments in education is undeniable, it should not be referred to as "experiential learning". As previously explained, experiential learning is referred to a methodology that students will experience different scientific experiments even before obtaining the theoretical concepts governing them.

This paper is a summary report of the early phases of a project undertaken by the authors to incorporate experiential learning into lower level engineering courses. Our focus in this phase of the project is a first year course on Logic (Digital) Circuits and Computer Design, taught at the School of Engineering Science at SFU (ENSC-150).

The paper is organized as follows: Section 2 includes the background and literature review. Section 3 presents the experiential learning example used in ENSC-150 followed by a summary of students' experience. Finally, Section 4 provides a summary of this paper and the future directions of this project.

\section{BACKGROUND AND LITERATURE REVIEW}

Experiential learning is the process of making meaning from direct experience, i.e., "learning from experience [3]. Aristotle once said, "For the things we have to learn before we can do them, we learn by doing them" [4]. A definition for Experiential Education by the Association of Experiential Education states, "Experiential Education is a process through which the learner constructs 
knowledge, skill, and value from direct experience" [5]. The idea of "Experiential Learning" was first reflected in writings of John Dewey [6] and later popularized by many educational experts, such as David A. Kolb. Some researchers have distinguished between "Experiential Learning" and "Experiential Education", in that experiential learning relies solely on the individual and does not necessarily require a teacher, whereas many others have used the two terms interchangeably [3]. Obviously, it is the second school of thought (integration of experiential learning and education) that can potentially be applied to educational settings such as degree programs at university levels.

The four critical steps associated with experiential learning are 1) Action, 2) Reflection, 3) Abstraction, 4) Application (See Fig. 1). This circular procedure will be initiated with an experience and followed by reflective observation. Observations will then help a person to form general rules and modify his experience [3].

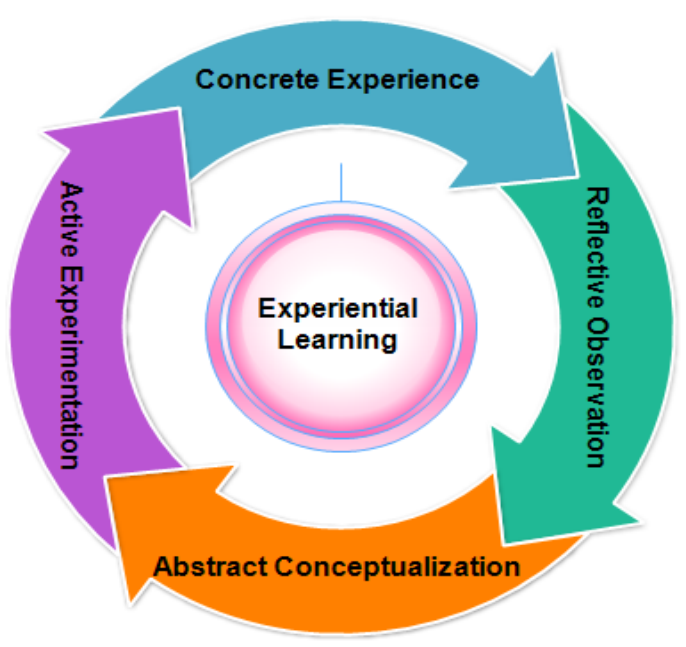

Fig. 1. Experiential Learning, circular diagram.

Enormous amount of our everyday knowledge is obtained through experiential learning. In other words, we experience various situations before understanding the rules governing them. For example, the process of language learning that a child will experience could vividly express the steps necessary for experiential learning. The revolution in foreign language education in which students will experience various concepts before acquiring any sense of grammar might have originated from experiential learning theory.

Experiential learning could also be applied to higher education .One very good example could be the experiential learning program at Nelson Mandela Metropolitan University in South Africa where students are given the chance to be exposed to various industrial fields such as administration, drawing, surveying, design, contracts, construction, and material testing. The students should pass this course successfully to obtain national diploma in civil engineering [7]. Experiential learning strategies have also been used in one of the Mechanical engineering courses at University of Chile [8]. There are several other universities around the world which have tried to apply experiential learning methods to their education system [9-10]. Among them is McMaster University, Ontario, Canada. They came up with a practical proposal referred to as ExCEL, "Engineering Center for experiential learning ". The prospective of this proposal is to construct a building which designed and managed with the students,[10]. This plan could be considered as a good model for future engineering education system where students will have the opportunity to join different clubs and societies to manage various team projects and be engaged in the ongoing experiments.

\section{EXPERIENTIAL LEARNING IN ENSC-150}

\subsection{Experiential Learning Example}

During the first phase of this project, we worked on incorporation of experiential learning in ENSC-150, a first year course in Logic Circuits, taught at the School of Engineering Science (ENSC) at SFU. In this course students are expected to learn how logic blocks can be designed and employed to construct simple digital devices. Combinational and sequential logic designs are the main topics covered in this course. The course has large enrolments (above 100 students) and includes lecture and tutorials but no laboratory component.

An example of a digital device which can be introduced to students in the advanced stages of this course is a digital clock. In the conventional method of teaching, the building blocks of this digital clock, i.e. flip flops, are first introduced to students, followed by the design procedure of the counters (which will count the seconds, minutes, and hours), and finally the details of how each counter is controlled and is reset after going through its cycle (for example the "seconds" counter is reset to zero after reaching to the number 59 , and this should trigger the "minutes" counter to increment by 1). In effect, students start by going through the theoretical steps of design resulting in the design of this digital clock.

If instead of the following the conventional method, we were to use the concept of experiential learning by adhering to its true definition, the students would be asked to start by experiencing with an actual digital clock, analyze the circuit inside it, figure out the building blocks of the clock and understand the interaction of the logic signals within the clock. Obviously, this is not possible in practice! 
The challenges faced here are the large enrolment in class, lack of a laboratory component in the syllabus of the course, and last but not least the fact that it is not possible to open and see the circuit inside an integrated digital circuit. Thus the approach we took here was a combination of theoretical (conventional) and experiential learning methods.

First of all, we used a logic simulation program, called DesignWorks, to enable the students to see the function of a various digital circuits and be able to make changes and modifications to circuits and see the results.

We presented this experiential learning example in the form of an assignment. We presented the students with a simplified logic circuit which exists inside a digital clock. This clock consists of three parts (See Fig. 2.). Part A, Receives a clock pulse of frequency $1 \mathrm{~Hz}$ and counts and displays the "seconds". Part B, Receives a clock pulse of frequency 1 pulse per minute from Part A, and counts and displays the "minutes". Part C, Receives a clock pulse of 1 pulse per hour from Part B, and displays the hours.

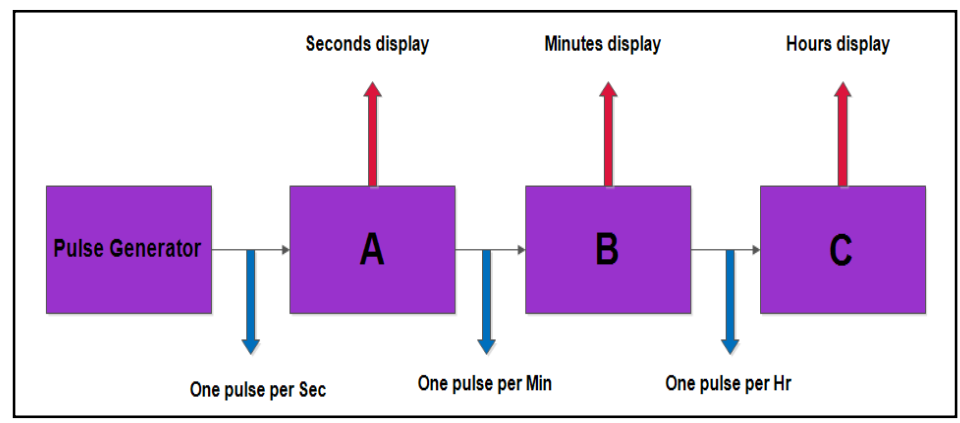

Fig. 2. Block diagram of a digital clock

Students were provided with the schematic of the circuits inside of Parts A and B. Fig. 3 shows the circuit for part A, counter of the "seconds". DesignWorks simulation files were also provided to the students so that they could run the simulation and observe how Parts A and $\mathrm{B}$ of the digital clock work and how they are related to each other. It should be noted that at this point the students had already learned about JK-flip flops, but they had not yet seen the structure of the counters used in this example.

The students were asked to run the simulations for Parts A and B, explain the function of these parts and demonstrate their understanding of how the counters for second and minute work and when and how they are reset. Students were then asked to design Part $\mathrm{C}$ of the clock and add it to the circuit, such that a complete clock which counts and displays the Hours, Minutes, and Seconds is simulated. They were also asked to include a sevensegment display showing the letters " $\mathrm{A}$ " and "P" representing "AM" and "PM", respectively. At the end, students had to complete a questionnaire about their learning experience during this assignment in comparison to their conventional assignments.

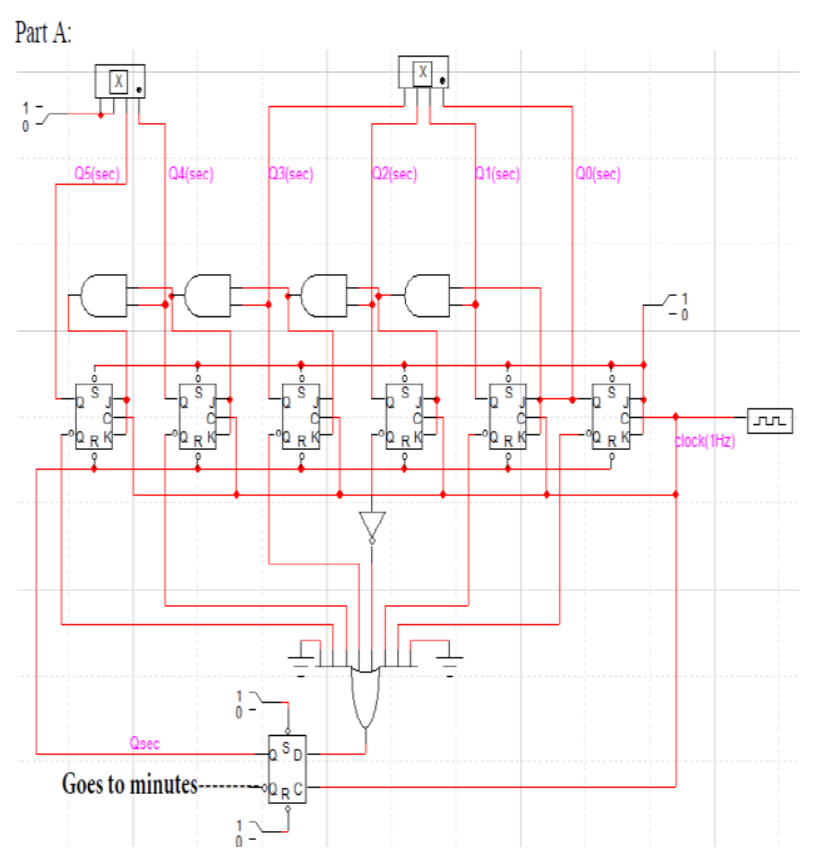

Fig. 3. Digital circuit inside of Part A, this circuit counts the seconds.

\subsection{Students' Experience}

The main questions asked of students in the questionnaire were:

1) On a scale of 1 to 5 rate how you prefer the experiential method over the conventional method (1: not preferred, 2: less preferred, 3: equally preferred, 4: more preferred 5: strongly preferred)

2) Comment on the differences between the two methods.

Sixty-seven students completed the questionnaire. A summary of their answers to Question (1) is shown in 4. More than $37 \%$ of the students favored the experiential learning method compared to $28 \%$ who preferred the conventional method. The rest of the students did not favor one method over the other.

As for the students' feedback in form of comments, many of the students found this experiment to be interesting and they mentioned that they look forward to be involved in more experimental work in future courses. The experiential method being more challenging and time consuming was among the drawbacks of this method mentioned by some of the other students. 


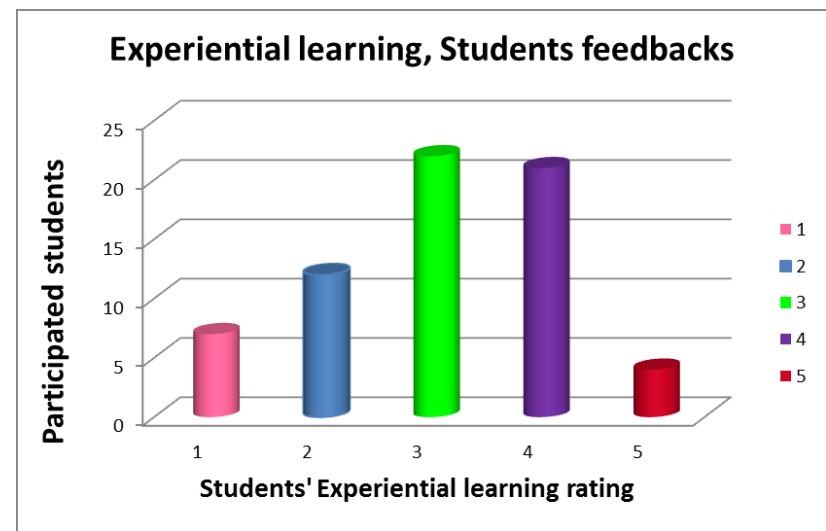

Fig. 4. Students' feedback on experiential learning vs. the conventional method.

Obviously, an important criterion for evaluating the effectiveness of this method would be to measure the learning outcome and level of understanding of students who were provided with this method of learning compared to students who had learned the same concept through the conventional educational method. We plan to implement and measure this criterion in the next phase of this project as explained in the next section.

\section{SUMMARY AND FUTURE DIRECTIONS}

This article is a report of the first phase of a project on incorporation of experiential learning in lower division courses at the School of Engineering Science at Simon Fraser University. Our focus during this phase was a first year course in Digital Circuits. The main challenges for incorporation of experiential learning in this course are large class enrolment, lack of laboratory component in the syllabus of the course, and the introductory level of the course.

Taking these limitations into account, we used a simulation software to enable students to simulate logic circuits while learning about the theory behind each circuit. Furthermore, as an experiential learning assignment we asked the students to find out how a digital clock worked by first experiencing the simulated version of the device. More than $37 \%$ of the students said that they preferred their learning experience through the experiential learning method compared to the conventional method.

In continuation of this work, we plan to expand this work by adding more experiential learning examples to this course as well as incorporating experiential learning examples into other lower division courses, such as Electrical Circuits or Electronics Circuits. We also plan to compare the learning outcome of students who have been learning a concept by first experiencing it, i.e., through experiential learning, with a control group who have learned the same concept through conventional lecture setting method. This can only be achieved if we have several such examples in each course, in order to maintain fairness and uniformity among the students, i.e., each student should get equal number of chances to learn through each learning method.

\section{Acknowledgements}

The authors wish to thank the "Teaching and Learning Center" at SFU for providing funding for this project through the "Teaching and Learning Development Grant".

We also wish to thank Mr. Rio Li, one of the teaching assistants of ENSC-150, for his help in developing the experiential learning example used in the project and reviewed in this paper.

Finally, we also wish to thank Dr. Lila Torabi and Mr. Amir Kassaian who collaborated with the first author during the early stages of this project.

\section{References}

[1] http://www.sfu.ca/experiential/ ( accessed May 1, 2013)

[2] http://electrical-and-

computer.egr.vcu.edu/undergraduate/experiential/( accessed May 1, 2013)

[3] Christian M. Itin " Reasserting the Philosophy of Experiential Education as a Vehicle for Change in the 21st Century" The Journal of Experiential Education, 1999, P 91-98

[4] Bynum, W. F. and Porter, R. Oxford Dictionary of Scientific Quotations, Oxford University Press,2005

[5] Luckmann, C. "Defining experiential education". Journal of Experiential Education, 1996,P 6-7

[6] John Dewey, "Democracy and Education by John Dewey 1916 " Chicago Journal, Published by university of Chicago press(Spring/Fall 2008) Vol. 5, No. 1/2 , pp. 8795

[7] http://civileng.nmmu.ac.za/Experiential-LearningProgramme (accessed April 25, 2013)

[8] http://www.seas.virginia.edu/students/experiential/(accessd April 25, 2013)

[9] http://electrical-andcomputer.egr.vcu.edu/undergraduate/experiential/( accessed April 25, 2013)

[10] http://www.eng.mcmaster.ca/excel/ (accessed May 1, 2013) 